\title{
What Makes a Quantum Organization?
}

It is in the very nature of "quantum" that no quantum organization would be defined by a set blueprint or formula. Each will adapt Quantum Management Theory to suit the needs and demands of the field of activity or industry in which it operates. Each will evolve its own organizational culture. We will see in the following four chapters how differently the Haier Group (a manufacturing industry) in China, and its American subsidiary GE Appliances, and Roche Pharmaceutical in India (operating in the healthcare sector) have shaped their quantum organizations, and the different company cultures to which this has given rise. But there are several characteristics that will be common to any such organization, and these derive from the defining principles of quantum thinking outlined in Chapter 2.

- A quantum organization is holistic: Quantum systems are holistic. The whole organizes the parts, and every part is related to and partially defined by its relationships to the other parts. In quantum physics, relationship helps to create further facts and new realities. Events always happen in a context.

In today's interdependent and globally interconnected business world, everything is related to everything. A quantum organization will see itself as a boundaryless, non-hierarchical living system in which every element of the system is defined through its relationship to all other elements.

(C) The Author(s) 2022

D. Zohar, Zero Distance, https://doi.org/10.1007/978-981-16-7849-3_15 
Thus it will have infrastructures and a culture that encourage and build relationships-between leaders and employees, between employees and their colleagues, between divisions and functional groups, and between the organization and its larger ecosystem-customers, the community, society as a whole, and the natural environment. Mechanistic, Taylorian models of the organization as divided into siloed divisions and functions, often set to compete against one another, cannot build these creative relationships. Nor can models of a corporate world consisting of companies acting as isolated islands, each ruthlessly pursuing its own self-interest. Cobbled together out of separate, uncoordinated parts and companies and yet impinged upon from every direction, these old models of conflict and confrontation must give way to new models of dynamic integration and cooperation. The integrity of individual concerns must be protected, while at the same time drawing all parts into a larger working whole.

- A quantum organization will be agile, responsive, and adaptive: Quantum and complex adaptive systems are indeterminate, or at least unpredictable. They are poised at the edge between order and chaos, between actuality and potentiality, and their indeterminacy makes them flexible, responsive to their environments, and primed to evolve in any direction.

Today's business world is complex, chaotic, and subject to continuous rapid change: technological, social, and geopolitical, changing customer and employee needs and expectations. Companies must be able to adapt and respond to all this-quickly! Mechanistic, Taylorian patterns of fixed, functional roles and rigidly organized, hierarchical structures for management and control, make these systems unwieldy and slow. Taylorian companies are heavy, lumbering dinosaurs in an age where light, winged birds command supremacy. The infrastructures of a quantum organization must be less like Meccano or Lego and more like plasticine, which can take any shape and be changed at will. Their products and/or services must be constantly innovative.

As I wrote earlier, a quantum organization should function more like a jazz jam session. It should have infrastructures and a culture that allow the free play of uncertainty and experimentation, where different questions can be asked, different goals, products, and functions considered. 
Roles will be less fixed, employees encouraged to play "different instruments," to take risks and experiment with the "score." The quantum leader sees him/herself as holding the space where the background theme can emerge.

And finally, a quantum organization should not fear chaos. The ancient Chinese knew that yin/yang, the dark and the light, order balanced with chaos, is the nature and dynamic of the Tao, the Way of the Universe. Today's living quantum science (complexity theory) teaches us that new order arises only out of chaos. When my then 2 -year-old daughter arrived home from playgroup one day to find that our house had been cleaned and all her toys neatly stacked away on shelves, she protested, "Too much space! We need some mess!" And she instantly set about making some. The mess made the house "home" for her, a place where she could play creatively. A home with too much order is like a society with too many rules or a company with too much bureaucracy. Too much order, too much tidiness, too much adherence to plans, is a form of imposed, outside control that dampens down the creativity of a system. As the ancient Greeks taught, "In the beginning was chaos, vast and dark....the void from which all forms arise, and to which they may return" (Hesoid, Theogony).

- A quantum organization must be bottom-up, self-organizing, and emergent: Quantum systems and complex adaptive systems are selforganizing and emergent. Each new whole constructed through relationship is always greater than the sum of its parts. Taking advantage of chaos and uncertainty, they are creative, always generating surprise, greater complexity, and new realities. These systems ensure their sustainability by constantly mining potentiality.

Companies today must be continuously innovative to ensure sustainability. We have seen that the RenDanHeyi management model ensures this, relying on bottom-up self-organization to do so. In the quantum organization, employees must be turned into responsible leaders in their own right, free to organize themselves and their work and to make decisions-not just self-organized, but also self-motivated, free to reinvent their jobs, their products, and their services in cocreative dialogue/interaction with customers and each other. Middlemanagement bureaucrats must be removed, and the CEO must surrender 
most or all of the power previously reserved to him/her. As we have seen, the quantum leader leads with a hands off, light-touch approach, serving his/her employees more as a mentor or coach and providing them with the resources they determine they need. This guarantees the emergence of an ever new, fit for purpose organization capable of constant adaptation and innovation.

- A quantum organization will thrive on diversity: Quantum and complexity science is both/and rather than either/or. Matter consists of particles and waves, and has the potentialities of each. Quantum systems explore many paths from A to B; living systems thrive and evolve through multiple mutations.

The quantum organization will abandon the old vision of one truth, one best way, perhaps one unambiguous product line, and instead take as its guiding principle: both/and, a plural way of accommodating the multiplicities and diversities of markets, customers, and employee potential. "My way" must give way to shared vision, shared opportunity, shared responsibility, and dialogue that recognize the validity of many paths from $A$ to $B$ and the infinite potential of both market opportunities and employee innovative skills. There will be infrastructures that mix levels of responsibility, teams that represent assorted educational, functional, and professional skills and backgrounds, thus assuring different styles of thinking for meeting challenges and solving problems, different products and different services suited to different users-all designed "to let a thousand flowers bloom." And there will be both some directive principles and the free-flowing lack of fixed structures, as appropriate to keep the ship on course while allowing the benefits of self-organization.

- A quantum organization will be eco-friendly and eco-systemic: Normal ecology concerns itself with protecting the natural environment. "Deep ecology" is more broadly concerned with life on earth as a total human/environmental ecosystem, a human meaning and valuecentered dimension that is in symbiosis with a nonhuman but life-centered dimension. Quantum Management Theory adds the dimension of "alignment with the cosmic order." 
A quantum organization both safeguards the environment and the natural order, and creates value for the human order-its shareholders and customers, its employees, and its community. Thus it is both eco-friendly and it makes itself the center of a human ecosystem. This ecosystem includes the community as well as internal, cooperative, often partnered relationships between teams and/or microenterprises within the organization and external ones with other companies. (See description of Haier ecosystem in next chapter.)

Like all mechanistic institutions, the Taylorian company assumes a natural dichotomy between the human world and the rest of creation. Newtonian organizations use their environment, they exploit nature's resources, just as they exploit their own employees and set themselves apart from the communities in which they are located-often polluting their air and waterways. For most of these companies, even the customer is "out there," "other." The quantum organization knows that it is in nature and of nature, in the community and of the community. It recognizes that companies are co-creative partners in the earth's ecosystem, both as dependents and as protectors. It replaces the coal and oil swilling machines of the Industrial Age, that have polluted the earth's environment and created a climate crisis that now threatens business as much as everyone and everything else, with green technology, and it finds ways to detoxify its waste. Quantum organizations devote research time and money to finding affordable solutions to community needs that impact the environment. They safeguard the natural order by making eco-friendly products for the market, and do so using eco-friendly manufacturing techniques.

- A quantum organization is vision-centered and value-driven. In Newtonian physics, which assumes a split between the observer and what he/she observes, the purposes, attitudes, and values of the observer are thought to play no role in what is observed. Newtonian science is "objective." But quantum science describes a "participative universe" in which the observer and the observed have a co-creative relationship. The question a scientist asks, the experiment that is done, determines what is observed. The quantum scientist's purposes, values, and assumptions thus frame the outcome of his/her experiments. 
The old, business-as-usual model is focused on products, profitmaximization, and a transactional relationship with shareholders and customers. These companies decide what products to offer the market, and often manipulate public and market taste to make it want their products. They try to create situations of scarcity or discontent, and feed on modern society's illusion that personal and spiritual emptiness can be filled with things. Often the market fails, or ceases, to respond. The customers become bored or jaded, and the companies that have tried to satisfy them fail.

By contrast, the focus of a quantum organization is its sense of purpose, the opportunities, benefits, and services brought to the customer's overall lifestyle or needs, and a co-creative and mutually beneficial relationship with customers/users. Quantum organizations bring value to usershigh-quality products and services, products and services that enhance the quality of users' lives. Such products and services make homes more efficient or user-friendly, may add beauty and balance to the home environment, improve users' health, and perhaps even add meaning to users' lives. Profit, and thus shareholder value, are still crucially important, but these are framed in terms of long-term sustainability rather than short-term benefit. And quantum organizations are ethical.

A food company putting junk food laden with fat, salt, and sugar onto the market when it knows full well these products are making buyers ill is not a quantum company. Pharmaceuticals that bury reports about dangerous or lethal drug side-effects, and oil companies that bribe "expert" scientists to write reports denying climate change are not quantum companies. Quantum companies know they can make healthy profits while giving their customers good food and safe medicine, while also adopting measures that protect the environment. They reject short-term profit maximization at any cost measures and instead build long-term customer loyalty and trust that also ensures their own longterm sustainability. In one of my earlier books, I described this ethical, long-term, high value approach as building "spiritual capital." Each of the companies I profile in the following chapters has adopted it in some measure. 
Open Access This chapter is licensed under the terms of the Creative Commons Attribution-NonCommercial-NoDerivatives 4.0 International License (http:// creativecommons.org/licenses/by-nc-nd/4.0/), which permits any noncommercial use, sharing, distribution and reproduction in any medium or format, as long as you give appropriate credit to the original author(s) and the source, provide a link to the Creative Commons license and indicate if you modified the licensed material. You do not have permission under this license to share adapted material derived from this chapter or parts of it.

The images or other third party material in this chapter are included in the chapter's Creative Commons license, unless indicated otherwise in a credit line to the material. If material is not included in the chapter's Creative Commons license and your intended use is not permitted by statutory regulation or exceeds the permitted use, you will need to obtain permission directly from the copyright holder.

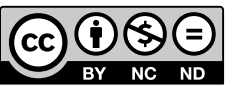

